\title{
ПСИХОФИЗИОЛОГИЧЕСКИЕ КОРРЕЛЯТЫ ПРЕДСТАВЛЕНИЯ ДВИЖЕНИЙ ТВОРЧЕСКОГО И НЕ ТВОРЧЕСКОГО ХАРАКТЕРА У ИССЛЕДУЕМЫХ С РАЗНЫМ УРОВНЕМ ТАНЦЕВАЛЬНОГО МАСТЕРСТВА
}

\author{
Мария Игоревна Наумова \\ аспирант \\ Южный федеральный университет \\ 2. Ростов-на-Дону, Россия \\ E-mail: botanik.66@mail.ru \\ Людмила Александровна Дикая \\ кандидат психологических наук, дочент \\ Южный федеральный университет \\ 2. Ростов-на-Дону, Россия \\ E-mail:dikaya@sfedu.ru \\ Игорь Владимирович Наумов \\ кандидат философских наук, дочент \\ Южный федеральный университет \\ 2. Ростов-на-Дону, Россия \\ E-mail: ivnaumov@sfedu.ru \\ Евгений Сергеевич Кулькин \\ старший преподаватель \\ Северо-Кавказский институт-филиал РАНХиГС \\ 2. Пятигорск, Россия \\ E-mail: in_house@mail.ru
}

Исследованиевыполнено в рамкахгосударственногозадания Министерства образования и науки РФ, проект № 2141

В статье обоснована актуальность изучения психофизиологических коррелятов представления движений творческого и не творческого характера у исследуемых с разным уровнем танцевального мастерства. Разработанный методический инструментарий и результаты исследования могут быть использованы при разработке методик и технологий профессионального 
обучения танцоров, при разработке психологчческих и психофизиологических методов и приемов развития творческого потенциала у танцоров, в проведении танцевально-экспрессивной психотерапии.

Описаны методика и процедура проведения эмпирического исследования. В исследовании приняли участие 60 человек в возрасте от 18 до 25 лет, из них: 20 профессиональных танцоров, которые достигли высокого уровня мастерства в спортивно-эстрадных танцах; 20 начинающих танцоров, которые имеют только базовый опыт в спортивно-эстрадных танцах и не получили завершенной, всесторонней подготовки, и 20 человек, никогда не занимавшихся танцами или другими видами спорта (контрольная группа) на профессиональном или любительском уровне.

В данном исследовании участникам предлагалось представить движения творческого и не творческого характера. В качестве представления движений не творческого характера выступило «представление мостика и переворота назад»; в качестве представления движений творческого характера-«оригинальный танец-импровизация».

В исследовании применен метод электроэнцефалографии. Изучались сила и характер распределения когерентных связей коры головного мозга у участников исследования при представлении движений. Выделенные на основе результатов проведенного эмпирического исследования психофизиологические корреляты представления движений дифференцированы на основные, проявляющиеся у всех участников исследования и не зависящие от характера движений, и вариативные, отражающие уровень профессионального танцевального мастерства участника исследования и характер представляемого движения. К основным компонентам психофизиологических коррелятов отнесены высокая внутри- и межполушарная когерентность в тета-, альфа1,2-диапазонах. В рамках вариативных компонентов выявлен ЭЭГ паттерн при представлении движений творческого характера в бета-диапазоне по «оси творчества» (между передними отделами правого полушария и задними отделами левого) у профессиональных танцоров.

Ключевые слова: представление движений, электроэниефалография, когерентность, частотный диапазон, психофизиологические корреляты, профессиональные танцоры, начинающие танцоры, не танцоры, танцевальная импровизация, мысленное представление.

Для цитирования: Наумова М. И., Дикая Л. А., Наумов И. В., Кулькин Е. С. Психофизиологические корреляты представления движений творческого и не творческого характера у исследуемых с разным уровнем танцевального мастерства // Российский психологический журнал. - 2016. - Т. 13. - № 3. C. 152-177. 


\title{
PSYCHOPHYSIOLOGICAL CORRELATES OF REPRESENTATIONS OF CREATIVE AND NON- CREATIVE MOVEMENTS IN SUBJECTS WITH VARIOUS LEVELS OF DANCE SKILLS
}

\author{
Mariia Igorevna Naumova \\ Postgraduate student \\ Southern Federal University \\ Rostov-on-Don, Russia \\ E-mail: botanik.66@mail.ru \\ Liudmila Aleksandrovna Dikaia \\ Candidate of Psychology, Associate Professor \\ Southern Federal University \\ Rostov-on-Don, Russia \\ E-mail: dikaya@sfedu.ru \\ Igor' Vladimirovich Naumov \\ Candidate of Philosophy, Associate Professor \\ Southern Federal University \\ Rostov-on-Don, Russia \\ E-mail: ivnaumov@sfedu.ru
}

Evgenii Sergeevich Kul'kin

Senior Lecturer

The Russian Presidential Academy of National Economy and Public Administration

under the President of the Russian Federation

Pyatigorsk, Russia

E-mail: in_house@mail.ru

\section{Acknowledgments}

The study is supported the Ministry of Education and Science of the Russian Federation, project no. 2141

The paper focuses attention on the importance of studying the psychophysiological correlates of the representations of creative and non-creative movements in respondents with various levels of dance skills. The developed methodological tools and the results obtained can be readily used in the development of methods and techniques of professional training of dancers, as well as psychological and psychophysiological methods and techniques for the development of creativity in 
dancers, and carrying out a dance-expressive psychotherapy.

The authors described the methodology and procedure of the empirical study. The study involved 60 persons at the age from 18 to 25. The sample included 20 professional dancers with a high level of skill in variety and sports dance; 20 novice dancers with a basic experience in the field of variety and sports dance; 20 persons without any experience in dance or other sports (control group) at a professional or amateur level.

In this study, the respondents had to represent creative (an original dance improvisation) and non-creative (a bridge and somersaults back) movements.

The study used the method of electroencephalography. The authors studied the strength and character of the distribution of coherence connections of the cerebral cortex in respondents when representing the movements. The results of the empirical study made it possible to distinguish psycho-physiological correlates of representation of the movements. The authors differentiated these correlates as follows: the main, which manifested themselves in all the respondents of the study, and do not depend on the nature of movements; variable, which reflect the level of professional dancing skills of respondents and the nature of the represented movement. High intra- and interhemispheric coherence in the theta, alpha1, and alpha2 ranges are the main components of the psycho-physiological correlates. Among the variable components the study revealed the EEG pattern in the beta range on the "axis of creativity" (between the front divisions of the right hemisphere and posterior divisions of the left one) in professional dancers when representing the creative movements.

Keywords: representation of movements, electroencephalography, coherence, frequency range, psychophysiological correlates, professional dancers, novice dancers, not dancers, dance improvisation, mental representation.

For citation: Naumova M. I., Dikaia L. A., Naumov I. V., Kul'kin E. S. Psychophysiological Correlates of Representations of Creative and Non-Creative Movements in Subjects with Various Levels of Dance Skills. Russian Psychological Journal, 2016, V. 13, no. 3, pp. 152-177.

\section{Введение}

Исследования последних десятилетий в области психологии, психофизиологии и нейрофизиологии позволили существенно продвинуться в изучении феномена творчества. В настоящее время фокус внимания исследователей обращен на поиск мозговых коррелятов творческой активности представителей разных сфер искусства (музыкантов, художников, актеров, танцоров и т. д.) в условиях реальной или приближенной к реальной профессиональной деятельности [2]. 
Также за последнее время существенно возрос научный интерес к изучению роли мысленных образов в спортивной деятельности для повышения эффективности подготовки спортсменов и повышения их профессионального мастерства [4, 9, 11, 12, 13, 16, 17, 18, 19, 20, 21].

Тем не менее, работы, изучающие психофизиологию представления движения у танцоров, крайне редки $[3,13]$. А. Финк изучал альфа-активность ЭЭГ у профессиональных танцоров в сравнении с группой начинающих танцоров. Результаты его исследования позволили предположить, что наблюдаемые закономерности активации мозга во время творческого мышления, в частности, выраженная альфа-синхронизация в теменно-затылочных областях мозга у профессиональных танцоров во время мысленного создания танцев, могут быть результатом эффективного функционирования пространственной сети, где расположены образ тела или представления о перемещении в пространстве.

Фактически не изученными остаются психофизиологические основы профессионального становления спортивно-эстрадных танцоров, особенно на этапе высокого уровня профессионального мастерства, когда танцоры уже достаточно владеют техникой движений и приемами их выражения, и актуальным теперь для них становится танцевальное творчество. Функционирование мозговых систем, обеспечивающих мысленное создание нового танца, танцевальную импровизацию, остается неизученным.

Можно предположить, что мозговые сети, включенные в этот сложный процесс, представляют собой определенную интеграцию систем мозга, задействованных как при идеомоторной тренировке, так и при творческом воображении. Научный интерес представляет вопрос о характере взаимодействия этих систем. И если нейрофизиологические корреляты представления движений, с одной стороны, и творческого мышления у представителей сферы искусства, с другой, описаны в научной литературе, то вопрос функциональной мозговой организации творческого выражения движений все еще остается без ответа.

Между тем, по мнению представителей гуманистической психологии, творческий процесс по своим психологическим механизмам во многом схож с процессом психотерапии [7]. И актуализация собственного творческого потенциала с помощью экспрессивной терапии, танцевально-экспрессивных тренингов через раскрепощение собственных движений лежит в основе осознания и решения внутри- и межличностных проблем [10]. Изучение мозговой организации представления собственных движений различного и, прежде всего, творческого характера, позволит получить новый ценный инструмент актуализации творческого состояния.

Вышеизложенное позволяет признать в качестве актуальной и приоритетной задачи изучение основных тенденций и психофизиологических 
коррелятов представления движений творческого и не творческого характера у исследуемых с разным уровнем танцевального мастерства, которые могут быть полезны при разработке тренировочных программ для спортсменов, танцоров, позволяющих повысить их показатели в спортивной деятельности. Результаты исследования позволят глубже изучить психофизиологию двигательных отделов нервной системы. Их можно использовать для обучения планированию танцевального движения и повышению точности его выполнения.

\section{Методика проведения исследования}

Целью исследования является изучение психофизиологических коррелятов представления движений творческого и не творческого характера у исследуемых с разным уровнем танцевального мастерства.

В качестве гипотезы было выдвинуто предположение о том, что психофизиологические корреляты представления движений могут дифференцироваться относительно задач творческого и не творческого характера у исследуемых с разным уровнем танцевального мастерства.

Объект исследования - 60 человек женского пола в возрасте 18-25 лет, разделенные в зависимости от уровня танцевального мастерства на три группы:

1) профессиональные эстрадные танцоры в количестве 20 человек;

2) начинающие танцоры в количестве 20 человек;

3) студенты, никогда не занимающиеся танцами или каким-либо другим видом спорта, в количестве 20 человек.

В данном исследовании участникам предлагалось представить движения творческого и не творческого характера. В качестве представления движений не творческого характера выступило «представление мостика и переворота назад». Испытуемым была предъявлена следующая инструкция: «Постарайтесь представить, как вы непрерывно выполняете упражнение мостик из положения стоя, а затем переворот назад». Испытуемый должен мысленно через мостик перейти назад со стойки, затем закинуть одну ногу, перевернуться и вернуться в стойку. Упражнение представляется непрерывно, до тех пор, пока экспериментатор не остановит испытуемого (в течение 10 секунд).

Далее испытуемые выполняли представление движения творческого характера, т. е. «оригинальный танец». Представление движения творческого характера включало создание двигательного и танцевального образа (мысленное представление). В данном случае участники групп были проинструктированы мысленно, под определенную музыку, представить танец, который должен быть уникальным и оригинальным (танец-импровизация). Во время 
эмпирического исследования испытуемым предъявлялась одна и та же быстрая, ритмичная музыка в исполнении группы Muse под названием Supermassive Black Hole, во время звучания которой испытуемым нужно было мысленно придумать и исполнить оригинальный танец в своем воображении.

При выполнении задания у испытуемых регистрировали электроэнцефалограмму. В качестве перерыва между задачами испытуемые сидели в течение 1 минуты с открытыми глазами. Начало выполнения и окончания каждого задания фиксировалось на энцефалограмме в виде маркера.

В качестве фоновой пробы использовалось спокойное состояние, глаза закрыты. В качестве функциональных проб выступили «представление движения не творческого характера» и «представления движения творческого характера».

Регистрация ЭЭГ осуществлялась при помощи энцефалографа «Энцефалан», версия «Элитная-М» производства МТБ «Медиком» (Таганрог) в 21 стандартном монополярном отведении с ипсилатеральными ушными референтами.

Анализировались отрезки ЭЭГ длительностью 10 секунд, не имеющие артефактов. Рассматривались когерентные связи биопотенциалов коры мозга между отведениями в диапазонах частот: тета (4-8 Гц), альфа1 (8,010,5 Гц), альфа2 (10,5-13,0 Гц), бета (13-35 Гц).

Когерентные связи между отведениями для каждого частотного диапазона были сгруппированы в 12 видов: LHP - внутриполушарные короткие в передних отделах левого полушария, LHZ-внутриполушарные короткие в задних отделах левого полушария, LHPZ-внутриполушарные длинные между передними и задними отделами левого полушария, MHPмежполушарные в передних отделах коры, DLH-диагональные между передними отделами левого полушария и задними отделами правого, $\mathrm{RHP}$ - внутриполушарные короткие в передних отделах правого полушария, $\mathrm{RHZ}$ - внутриполушарные короткие в задних отделах правого полушария, RHPZ - внутриполушарные длинные между передними и задними отделами правого полушария, MHZ - межполушарные в задних отделах коры, DRH диагональные между передними отделами правого полушария и задними отделами левого полушария, SDRHLH - межполушарные длинные между симметричными отведениями, SKRHLH - межполушарные короткие между симметричными отведениями.

Для статистической обработки данных применялся многофакторный дисперсионный анализ ANOVA/MANOVA и сравнительный post-hoc анализ по критерию Фишера. Обработка осуществлялась при помощи пакета компьютерных программ Statistica 12.0 . 
Посредством дисперсионного анализа выявлен эффект взаимодействия факторов: Грynna (3 - профессиональные танцоры; начинающие танцоры; не танцоры) × Характер пробы (3 - фоновая проба, глаза закрыты; представление движения не творческого характера; представление движения творческого характера) $\times$ Вид когерентной связи (12). Поскольку влияние взаимодействия этих факторов на уровень когерентности было достоверным для каждого частотного диапазона, но с разной степенью значимости ( $F=26,32, p<0,0001$ для тета-диапазона; $F=19,56, p<0,0001$ для альфа1-диапазона; $F=24,06, p<0,0001$ для альфа2-диапазона; $F=17,65$, $\mathrm{p}<0,0001$ для бета-диапазона), мы обратились к post-hoc анализу (по критерию Фишера, p s 0,05) для сравнения выраженных когерентных связей при представлении движений творческого и не творческого характера у профессиональных и начинающих танцоров, а также не танцоров.

Далее приведены и описаны только достоверные различия $(p \leq 0,05)$.

\section{Результаты исследования}

На первом этапе мы провели сравнительный анализ показателей когерентности представления движений не творческого характера в сравнении с фоном и представления движений творческого характера в сравнении с фоном у исследуемых с разным уровнем танцевального мастерства в тета-, альфа1-, альфа2- и бета- диапазонах.

Когерентные связи, сила которых не изменилась в сравнении с фоном, далее в исследовании не рассматривались, т. к. они оказались не включенными в функциональную систему мозга, обеспечивающую представление танцевальных движений.

На втором этапе исследования проводился сравнительный анализ силы функциональных связей при представлении движений творческого характера, в отличие от не творческого у исследуемых с разным уровнем танцевального мастерства.

В тета-диапазоне у профессиональных танцоров при представлении движений творческого характера, в отличие от не творческого, выявлены более сильные межполушарные связи в задних отделах коры, внутриполушарные длинные, внутриполушарные короткие в передних и задних отделах левого полушария, межполушарные диагональные и внутриполушарные длинные между передними и задними отделами левого полушария. В то же время при представлении движений не творческого характера, в отличие от творческого, выявлены более сильные внутриполушарные короткие связи в передних и задних отделах правого полушария и межполушарные длинные связи между симметричными отведениями (таблица 2). 
Таблица 1.

Достоверные различия силы когерентных связей коры мозга в тета-, альфа1,2-, бета- диапазонах у исследуемых с разным уровнем танцевального мастерства, при решении задач творческого и не творческого характера относительно фона $(p \leq 0,05)$

\begin{tabular}{|c|c|c|c|c|c|c|}
\hline & \multicolumn{6}{|c|}{ Тета-диапазон } \\
\hline & \multicolumn{3}{|c|}{$\begin{array}{c}\text { Представление движений } \\
\text { не творческого характера } \\
\text { в сравнении с фоном }\end{array}$} & \multicolumn{3}{|c|}{$\begin{array}{c}\text { Представление движений твор } \\
\text { ческого характера в сравнении } \\
\text { с фоном }\end{array}$} \\
\hline & $\begin{array}{l}\text { Профессио- } \\
\text { нальные } \\
\text { танцоры }\end{array}$ & $\begin{array}{l}\text { Начина- } \\
\text { ющие } \\
\text { танцоры }\end{array}$ & $\begin{array}{c}\text { Не } \\
\text { танцоры }\end{array}$ & $\begin{array}{l}\text { Профессио- } \\
\text { нальные } \\
\text { танцоры }\end{array}$ & $\begin{array}{c}\text { Начина- } \\
\text { ющие } \\
\text { танцо- } \\
\text { ры }\end{array}$ & $\begin{array}{c}\text { Не } \\
\text { танцоры }\end{array}$ \\
\hline \multirow{8}{*}{$\begin{array}{c}\text { Сила } \\
\text { когерент- } \\
\text { ных свя- } \\
\text { зей по- } \\
\text { высилась } \\
\text { относи- } \\
\text { тельно } \\
\text { фона } \\
\text { (р } \leq 0,05)\end{array}$} & $\mathrm{RHZ}$ & SKRHLH & RHP & $\mathrm{MHZ}$ & $\mathrm{RHZ}$ & LHPZ \\
\hline & RHP & $\mathrm{RHZ}$ & RHPZ & RHP & $\mathrm{MHZ}$ & \\
\hline & RHPZ & $\mathrm{MHZ}$ & DRH & RHPZ & RHP & \\
\hline & DRH & RHP & LHP & LHZ & DLH & \\
\hline & LHPZ & DRH & LHPZ & DRH & LHP & \\
\hline & MHP & LHP & & LHP & SDRHLH & \\
\hline & & SDRHLH & & LHPZ & MHP & \\
\hline & & MHP & & MHP & & \\
\hline \multirow{10}{*}{$\begin{array}{c}\text { Сила } \\
\text { когерент- } \\
\text { ных свя- } \\
\text { зей по- } \\
\text { низилась } \\
\text { относи- } \\
\text { тельно } \\
\text { фона } \\
\text { (р } \leq 0,05)\end{array}$} & SKRHLH & $\mathrm{DLH}$ & $\mathrm{RHZ}$ & DLH & SKRHLH & $\mathrm{RHZ}$ \\
\hline & DLH & RHPZ & $\mathrm{MHZ}$ & SDRHLH & RHPZ & $\mathrm{MHZ}$ \\
\hline & LHZ & LHPZ & DLH & $\mathrm{RHZ}$ & LHZ & RHP \\
\hline & SDRHLH & & LHZ & & & DLH \\
\hline & & & SDRHLH & & & RHPZ \\
\hline & & & MHP & & & LHZ \\
\hline & & & & & & $\mathrm{DRH}$ \\
\hline & & & & & & LHP \\
\hline & & & & & & SDRHLH \\
\hline & & & & & & MHP \\
\hline \multirow{2}{*}{$\begin{array}{c}\text { Сила } \\
\text { коге- } \\
\text { рентных } \\
\text { связей от- } \\
\text { носитель- } \\
\text { но фона } \\
\text { не изме- } \\
\text { нилась }\end{array}$} & MHZ & LHZ & SKRHLH & SKRHLH & LHPZ & SKRHLH \\
\hline & LHP & & & & DRH & \\
\hline
\end{tabular}




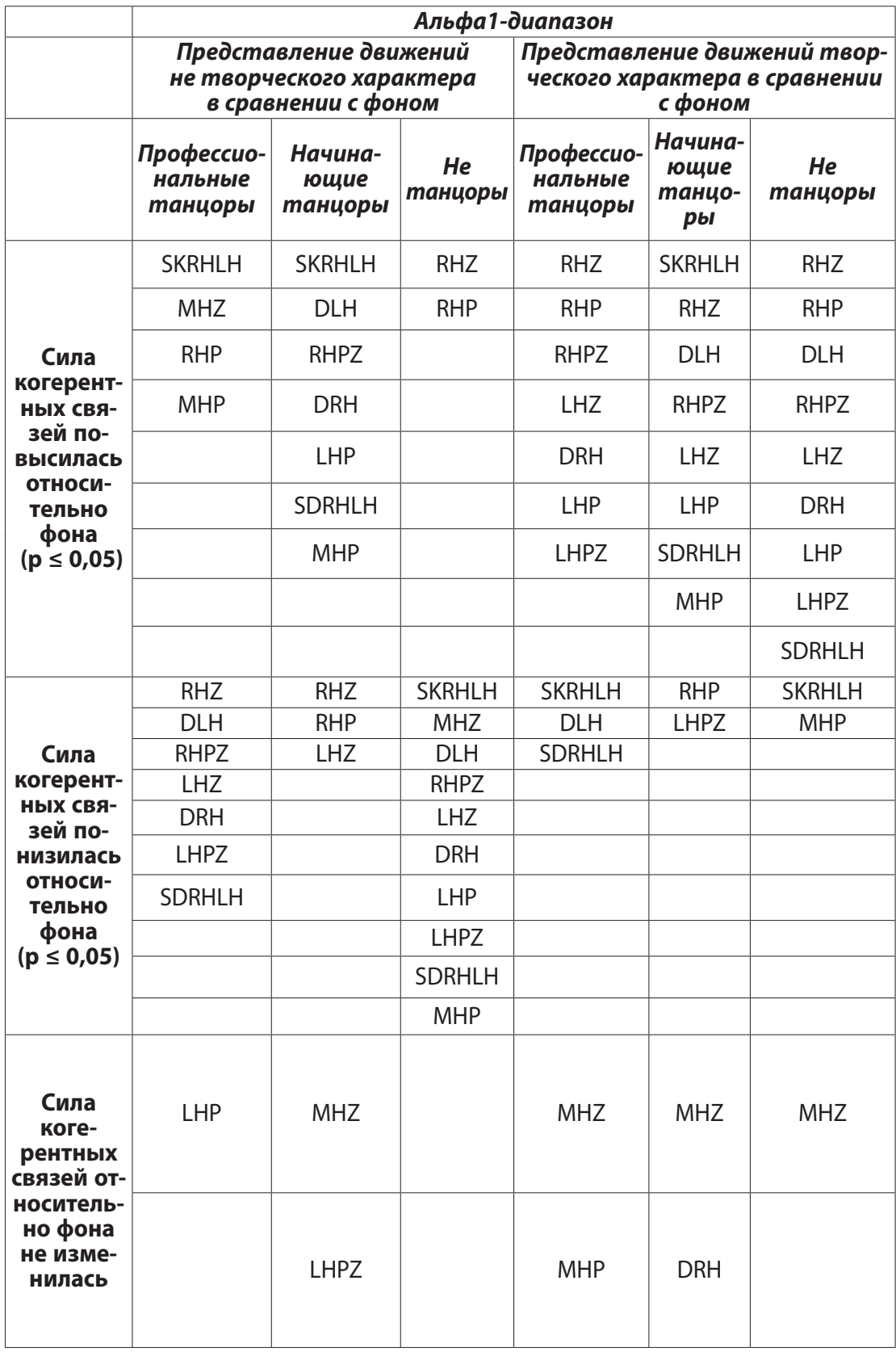




\begin{tabular}{|c|c|c|c|c|c|c|}
\hline & \multicolumn{6}{|c|}{ Альфа2-диапазон } \\
\hline & \multicolumn{3}{|c|}{$\begin{array}{c}\text { Представление движений } \\
\text { не творческого характера } \\
\text { в сравнении с фоном }\end{array}$} & \multicolumn{3}{|c|}{$\begin{array}{c}\text { Представление движений твор- } \\
\text { ческого характера в сравнении } \\
\text { с фоном }\end{array}$} \\
\hline & $\begin{array}{l}\text { Профессио- } \\
\text { нальные } \\
\text { танцоры }\end{array}$ & $\begin{array}{l}\text { Начина- } \\
\text { ючцие } \\
\text { maнцоры }\end{array}$ & $\begin{array}{c}\text { Не } \\
\text { танцоры }\end{array}$ & $\begin{array}{l}\text { Профессио- } \\
\text { нальные } \\
\text { танцоры }\end{array}$ & $\begin{array}{c}\text { Начина- } \\
\text { ющие } \\
\text { танцо- } \\
\text { ры }\end{array}$ & $\begin{array}{c}\text { Не } \\
\text { танцоры }\end{array}$ \\
\hline \multirow{8}{*}{$\begin{array}{c}\text { Сила } \\
\text { когерент- } \\
\text { ных свя- } \\
\text { зей по- } \\
\text { высилась } \\
\text { относи- } \\
\text { тельно } \\
\text { фона } \\
\text { (р } \leq 0,05 \text { ) }\end{array}$} & RHPZ & SKRHLH & DLH & SKRHLH & SKRHLH & DLH \\
\hline & $\mathrm{LHZ}$ & $\mathrm{MHZ}$ & $\mathrm{LHZ}$ & $\mathrm{RHZ}$ & RHP & $\mathrm{LHZ}$ \\
\hline & $\mathrm{DRH}$ & DLH & LHP & LHPZ & DLH & LHP \\
\hline & LHPZ & RHPZ & LHPZ & SDRHLH & RHPZ & LHPZ \\
\hline & MHP & & & & LHP & \\
\hline & & & & & LHPZ & \\
\hline & & & & & SDRHLH & \\
\hline & & & & & MHP & \\
\hline \multirow{8}{*}{$\begin{array}{c}\text { Сила } \\
\text { когерент- } \\
\text { ных свя- } \\
\text { зей по- } \\
\text { низилась } \\
\text { относи- } \\
\text { тельно } \\
\text { фона } \\
\text { (р } \leq 0,05)\end{array}$} & SKRHLH & $\mathrm{RHZ}$ & SKRHLH & RHP & $\mathrm{RHZ}$ & $\mathrm{RHZ}$ \\
\hline & $\mathrm{RHZ}$ & LHZ & $\mathrm{RHZ}$ & DLH & DRH & $\mathrm{MHZ}$ \\
\hline & $\mathrm{MHZ}$ & DRH & $\mathrm{MHZ}$ & LHP & & RHP \\
\hline & RHP & LHPZ & RHP & & & RHPZ \\
\hline & LHP & SDRHLH & RHPZ & & & $\mathrm{DRH}$ \\
\hline & SDRHLH & MHP & DRH & & & SDRHLH \\
\hline & & & SDRHLH & & & MHP \\
\hline & & & MHP & & & \\
\hline \multirow{5}{*}{$\begin{array}{c}\text { Сила } \\
\text { коге- } \\
\text { рентных } \\
\text { связей от- } \\
\text { носитель- } \\
\text { но фона } \\
\text { не изме- } \\
\text { нилась }\end{array}$} & DLH & RHP & & $\mathrm{MHZ}$ & $\mathrm{MHZ}$ & SKRHLH \\
\hline & & LHP & & RHPZ & LHZ & \\
\hline & & & & LHZ & & \\
\hline & & & & $\mathrm{DRH}$ & & \\
\hline & & & & MHP & & \\
\hline
\end{tabular}




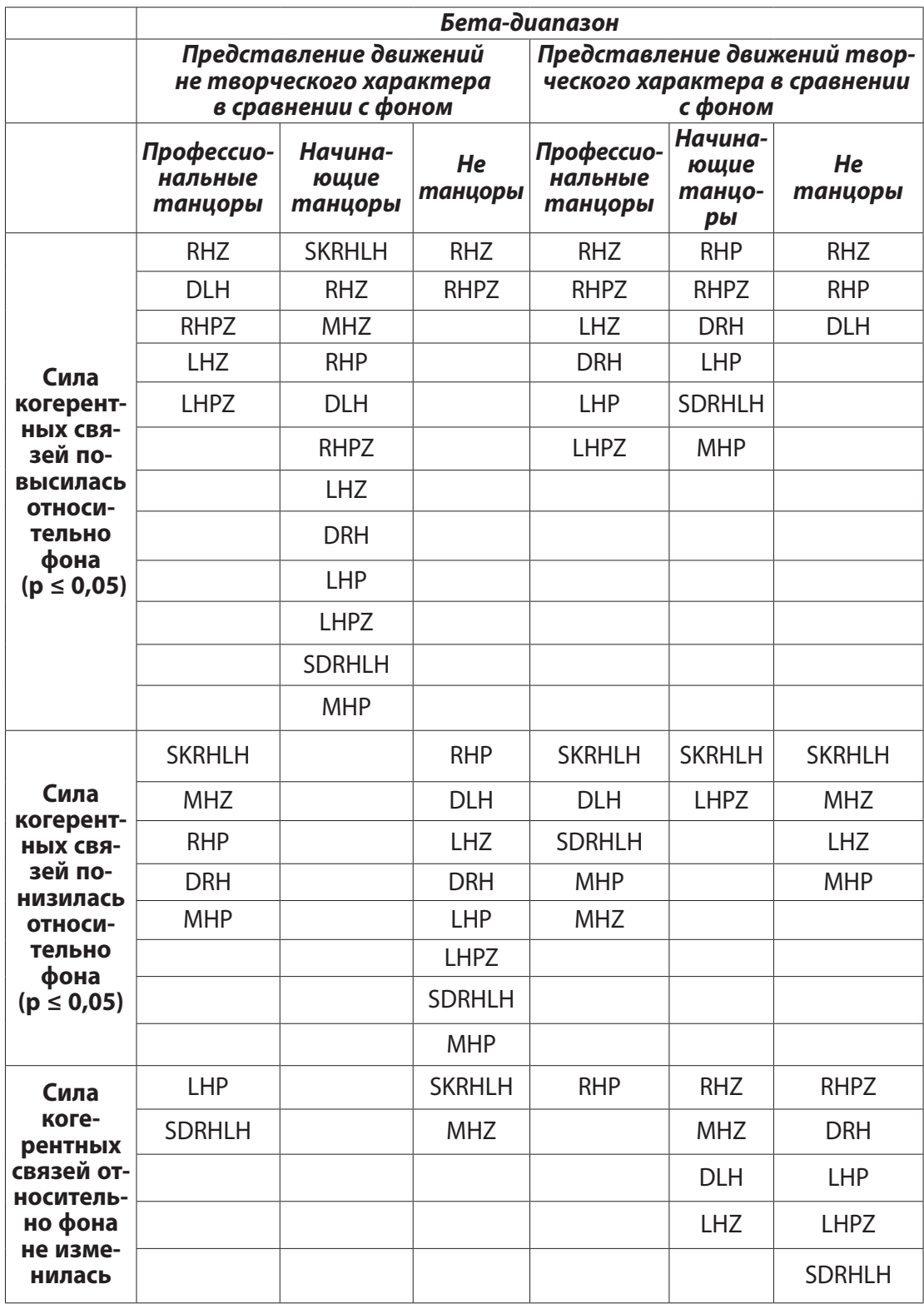

Примечание: соответствие названий видов когерентных связей их условным обозначениям представлено в тексте статьи. 
Таблича 2.

Достоверные различия силы когерентных связей коры мозга в тета-, альфа1,2-, бета- диапазонах у исследуемых с разным уровнем танцевального мастерства при решении задач творческого

и не творческого характера ( $\mathbf{p} \leq 0,05)$

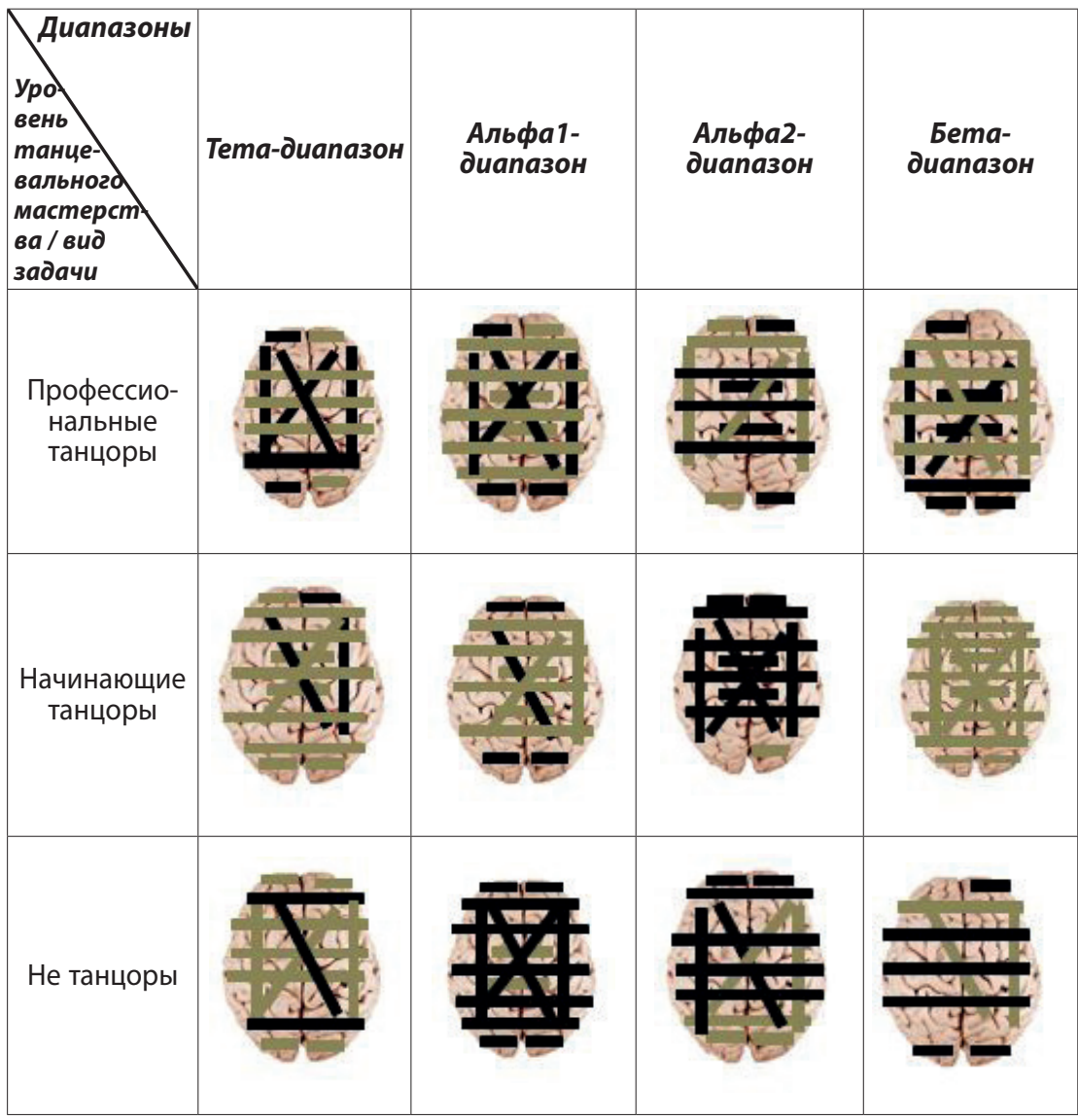

Условные обозначения:

когерентные связи выражены сильнее при представлении движений творческого характера, в отличие от не творческого;

когерентные связи выражены сильнее при представлении движений не творческого характера, в отличие от творческого.

У начинающих танцоров при представлении движений творческого характера, в отличие от не творческого, выявлены более сильные 
внутриполушарные короткие связи в передних отделах правого полушария, межполушарные диагональные между передними отделами левого полушария и задними отделами правого полушария, внутриполушарные длинные между передними и задними отделами правого полушария и межполушарные длинные связи между симметричными отведениями. В то же время, при представлении движений не творческого характера, в отличие om творческого, выявлены более сильные внутриполушарные короткие связи в задних отделах правого и левого полушария и в передних отделах левого полушария, межполушарные короткие связи между симметричными отведениями, межполушарные в передних и задних отделах коры и межполушарные диагональные между передними отделами правого полушария и задними отделами левого полушария (таблица 2).

У не танцоров при представлении движений творческого характера, в отличие от не творческого, выявлены более сильные межполушарные связи в передних и задних отделах коры и диагональные межполушарные связи между передними отделами левого полушария и задними отделами правого полушария. В то же время, при представлении движений не творческого характера, в отличие от творческого, выявлены более сильные внутриполушарные короткие связи, диагональные межполушарные связи между передними отделами правого полушария и задними отделами левого полушария, внутриполушарные длинные, межполушарные длинные между симметричными отведениями (таблица 2).

Итак, в тета-диапазоне у представителей всех исследуемых групп при представлении движений творческого характера, в сравнении с движениями не творческого характера, выявлены достоверно более сильные межполушарные диагональные когерентные связи $(p \leq 0,05)$ между передними отделами левого полушария и задними отделами правого. Также у всех участников исследования во время представления движений не творческого характера, в сравнении с движениями творческого характера, наблюдаются достоверно более сильные межполушарные длинные когерентные связи между симметричными отведениями и правополушарные короткие связи в задних отделах.

В альфа1-диапазоне у профессиональных танцоров при представлении движений творческого характера, в отличие от не творческого, выявлены более сильные внутриполушарные связи в задних отделах правого и левого полушария, а также в передних отделах левого полушария, диагональные межполушарные, внутриполушарные длинные связи. В то же время, при представлении движений не творческого характера, в отличие от творческого характера, выявлены более сильные межполушарные связи между симметричными отведениями, межполушарные связи в передних и задних отделах коры, внутриполушарные короткие связи в передних отделах правого полушария (таблица 2). 
У начинающих танцоров при представлении движений творческого характера, в отличие от не творческого, выявлены более сильные внутриполушарные короткие связи, диагональные межполушарные между передними отделами левого полушария и задними отделами правого полушария. В то же время, при представлении движений не творческого характера, в отличие om творческого, выявлены более сильные межполушарные связи между симметричными отведениями, внутриполушарные длинные между передними и задними отделами правого полушария, межполушарные диагональные между передними отделами правого полушария и задними отделами левого полушария, межполушарные связи в передних отделах коры (таблица 2).

У не танцоров при представлении движений творческого характера, в отличие от не творческого, выявлены более сильные внутриполушарные короткие связи, межполушарные в передних и задних отделах коры, межполушарные диагональные, внутриполушарные длинные, межполушарные длинные между симметричными отведениями. В то же время, при представлении движений не творческого характера, в отличие от творческого, выявлены более сильные межполушарные короткие связи между симметричными отведениями (таблица 2).

В альфа1-диапазоне у представителей всех исследуемых групп при представлении движений творческого характера, в отличие от не творческого, достоверно более сильно выражены межполушарные диагональные когерентные связи $(p \leq 0,05)$ между передними отделами левого полушария и задними отделами правого, сильные внутриполушарные короткие связи в передних и задних отделах левого полушария, а также в задних отделах правого полушария. При представлении движений не творческого характера у всех участников исследования наблюдаются достоверно более сильные межполушарные короткие когерентные связи между симметричными отведениями ( $p \leq 0,05)$.

В альфа2-диапазоне у профессиональных танцоров при представлении движений творческого характера, в отличие от не творческого, выявлены более сильные межполушарные связи между симметричными отведениями, внутриполушарные короткие связи в передних и задних отделах правого полушария. В то же время, при представлении движений не творческого характера, в отличие от творческого, выявлены более сильные внутриполушарные длинные связи, внутриполушарные короткие связи в передних и задних отделах левого полушария, межполушарные диагональные между передними отделами правого полушария и задними отделами левого полушария, межполушарные связи в передних отделах коры (таблица 2).

У начинающих танцоров при представлении движений творческого характера, в отличие от не творческого, выявлены более сильные межполушарные 
связи между симметричными отведениями, внутриполушарные короткие связи в передних отделах правого и левого полушария, межполушарные диагональные, внутриполушарные длинные, межполушарные связи в передних отделах коры. В то же время, при представлении движений не творческого характера, в отличие от творческого, выявлены более сильные внутриполушарные короткие связи в задних отделах правого полушария (таблица 2).

У не танцоров при представлении движений творческого характера, в отличие от не творческого, выявлены более сильные внутриполушарные короткие в передних отделах правого и левого полушария, межполушарные диагональные между передними отделами левого полушария и задними отделами правого, внутриполушарные длинные между передними и задними отделами левого полушария, межполушарные длинные между симметричными отведениями, межполушарные в передних отделах коры. В то же время, при представлении движений не творческого характера, в отличие от творческого, выявлены более сильные внутриполушарные короткие связи в задних отделах правого и левого полушария, межполушарные связи в задних отделах коры, внутриполушарные длинные между передними и задними отделами правого полушария, межполушарные диагональные между передними отделами правого полушария и задними отделами левого полушария (таблица 2).

В альфа2-диапазоне у всех участников исследования при представлении движений творческого характера наблюдаются достоверно более сильные внутриполушарные короткие когерентные связи в передних отделах правого полушария и межполушарные длинные когерентные связи между симметричными отведениями ( $\mathrm{p} \leq 0,05)$.

Выявленные у всех участников исследования достоверно более сильные внутриполушарные короткие когерентные связи в передних отделах левого полушария и в задних отделах правого полушария, внутриполушарные длинные связи, межполушарные связи в передних отделах коры, межполушарные диагональные когерентные связи между передними отделами правого полушария и задними отделами левого в альфа2-диапазоне дифференцируются в зависимости от характера представляемых движений (творческие, не творческие).

В бета-диапазоне у профессиональных танцоров при представлении движений творческого характера, в отличие от не творческого, выявлены более сильные межполушарные короткие связи между симметричными отведениями, внутриполушарные короткие связи в задних отделах правого и левого полушария, а также в передних отделах левого полушария, межполушарные связи в задних отделах коры, межполушарные диагональные между передними отделами правого полушария и задними отделами левого полушария, внутриполушарные длинные между передними и задними 
отделами левого полушария. В то же время, при представлении движений не творческого характера, в отличие от творческого, выявлены более сильные межполушарные диагональные между передними отделами левого полушария и задними отделами правого полушария, внутриполушарные длинные между передними и задними отделами правого полушария, межполушарные длинные между симметричными отведениями и межполушарные в передних отделах коры (таблица 2).

У начинающих танцоров при представлении движений не творческого характера, в отличие от творческого, наблюдается сильная когерентность во всех видах связей (таблица 2).

У не танцоров при представлении движений творческого характера, в отличие от не творческого, выявлены более сильные внутриполушарные короткие связи в передних и задних отделах правого полушария, а также в задних отделах левого полушария, межполушарные длинные между симметричными отведениями. В то же время, при представлении движений не творческого характера, в отличие от творческого, выявлены более сильные межполушарные диагональные связи между передними отделами левого полушария и задними отделами правого полушария, внутриполушарные длинные между передними и задними отделами правого полушария, межполушарные связи в передних отделах коры (таблица 2).

В бета-диапазоне у представителей всех групп при представлении движений не творческого характера, в отличие от движений творческого характера, наблюдаются достоверно более сильные межполушарные диагональные когерентные связи между передними отделами левого полушария и задними отделами правого, а также внутриполушарные длинные связи между передними и задними отделами правого полушария и межполушарные связи в передних отделах коры ( $\leq \leq 0,05)$.

В бета-диапазоне у всех участников исследования выявлены достоверно более сильные внутриполушарные короткие связи в задних отделах обоих полушарий, межполушарные длинные когерентные связи между симметричными отведениями, которые дифференцируются в зависимости от характера представляемых движений (творческие, не творческие).

\section{Обсуждение результатов}

Высокая сила когерентных связей выявлена у профессиональных танцоров при представлении движений творческого характера, в отличие от остальных групп испытуемых в тета-диапазоне. Функциональная роль тета-ритма рядом авторов связывается с рабочим напряжением, механизмами квантования извлекаемых из памяти энграмм, с процессами направленного внешнего внимания и сканирования памяти, коррелятами различной результативной 
целенаправленной деятельности человека [5, 8]. В свете современных представлений усиление тета-активности в передних и задних отделах коры головного мозга у человека рассматривается как проявление повышенной активации. На основании вышеизложенного нами было сделано заключение о том, что показатели когерентности в тета-диапазоне могут отражать рабочее напряжение процесса создания танцевального образа, а также являться признаком направленного внешнего внимания у участников нашего исследования.

Необходимо отметить, что в нашем исследовании у профессиональных танцоров в спокойном состоянии и при представлении движений творческого и не творческого характера выражены более сильные когерентные связи практически во всех частотных диапазонах, особенно в альфа1,2-диапазонах, в отличие от начинающих танцоров и не танцоров. Результаты исследования показывают, что альфа-синхронизация возрастает по мере роста профессионализма (не танцоры, начинающие танцоры и профессиональные танцоры), это подтверждают результаты работ А. Финка, в которых профессиональные танцоры также показывают большую по сравнению с новичками альфа-синхронизацию при мысленном представлении танцев. Альфа-синхронизация отражает процесс внутренней обработки, например, когда необходимо удерживать информацию во внимании. Альфа-синхронизация во время творческого мышления может отражать состояние повышенной концентрации или настороженности задействованных цепей, также она может означать, что обработка информации в конкретных областях мозга с меньшей вероятностью беспокоит параллельные когнитивные процессы до тех пор, пока происходит текущая генерация идеи [13].

Выявленную во время представления движений творческого характера альфа-синхронизацию ЭЭГ во фронтальных отделах мозга у всех групп испытуемых, как функциональный коррелят редуцированного состояния активной обработки информации в основных кортикальных сетях, A. Fink, B. Graif, A. C. Neubauer объясняют тем, что управляющие фронтальные зоны мозга временно должны рассогласоваться, когда возникает необходимость в новой или оригинальной обработке информации. Другими словами, они полагают, что испытуемые нуждаются во временном «выключении» контроля или наблюдении за поступлением обрабатываемой информации (которая, по-видимому, осуществляется фронтальными отделами коры), чтобы позволить уникальным или оригинальным идеям попасть в сферу сознания [13].

Во время представления движений творческого характера профессиональные танцоры показывают выраженную лево- и правополушарную альфа-синхронизацию, преимущественно в задних отделах мозга. По предположению A. Fink с коллегами, наблюдаемая в проведенном ими исследовании 
альфа-синхронизация в париетально-окципитальных отделах коры мозга, более выраженная у профессиональных, чем у начинающих танцоров, может служить в качестве механизма, ответственного за активное торможение или подавление отвлекающего и мешающего информационного потока от зрительной системы [14]. С другой стороны, выраженная синхронизация альфа-активности в теменно-затылочных областях мозга у профессиональных танцоров во время мысленного создания танцев может быть также результатом эффективного функционирования пространственной сети, где расположены образ тела или представления о перемещении в пространстве. Данные исследования позволяют предположить, что наблюдаемые закономерности активации мозга во время творческого мышления, в частности выраженная альфа-синхронизация в теменно-затылочных областях мозга, связаны с творческим стилем в целом.

Функциональная роль альфа1-ритма связывается современными исследователями с общим активационным состоянием, реализацией интуитивных процессов, внутренней обработкой информации, торможением иррелевантной информации для выполнения текущей задачи $[1,14]$. Выявленное в нашем исследовании усиление межполушарных связей в передних отделах мозга у профессиональных танцоров и начинающих танцоров во время представления движений не творческого характера, а у не танцоров-творческого характера, может свидетельствовать о подавлении познавательных процессов, не имеющих непосредственного отношения к выполнению задания.

Анализ когерентных характеристик в диапазоне альфа2-ритма показал различные для каждой исследуемой группы значения внутри- и межполушарных функциональных связей между определенными областями мозга в процессе представления движений не творческого характера и схожие значения в процессе представления движений творческого характера. Функциональная роль альфа2-ритма связывается современными исследователями со спецификой обработки информации при решении когнитивных задач. Предполагается, что правая передняя область вовлечена в спонтанную продукцию невербальных репрезентаций, а левая выполняет контроль, дополнительную оценку и анализ, обеспечивает целенаправленное извлечение информации из эпизодической и семантической памяти [6]. Из чего мы заключаем, что у профессиональных танцоров, начинающих танцоров и не танцоров во время представления движений творческого характера процесс основан на поиске возможных ассоциаций, спонтанной продукции образов. Тогда как у профессиональных танцоров, в отличие от других групп испытуемых, во время представления движений не творческого характера преобладают механизмы анализа, оценки имеющегося в памяти материала.

Когерентность в бета-диапазоне чаще всего ассоциируется с процессами 
сенсомоторной интеграции и удержанием информации, связанной с движениями, в рабочей памяти. У начинающих танцоров во время представления движений не творческого характера в бета-диапазоне выявлен высокий уровень межполушарного взаимодействия и внутриполушарного взаимодействия в обоих полушариях, что отражает сильное взаимодействие полушарий в процессе обработки образной информации. Высокочастотные диапазоны связывают с протеканием сложных когнитивных процессов, обеспечивающих объединение в общую картину отдельных показателей стимулов при дифференцировании абстрактных и конкретных слов при необходимости разграничения семантических значений разномодальных объектов [15, 22, 23]. Так, в бета-диапазоне у профессиональных танцоров во время представления движений творческого характера задействованы задние отделы коры головного мозга, возможно, это происходит в случае актуализации информации из памяти с целью генерирования оригинальных идей.

Во время представления движений творческого характера у профессиональных танцоров в тета-, альфа1-, бета- диапазонах наблюдается пространственная синхронизация нейронной активности по направлению «передние области правого полушария-задние области левого» [8]. Эту специфическую топологию пространственной синхронизации связывают с активацией творческой интуиции и называют «ось творчества». Тогда как у начинающих танцоров и не танцоров в тета-, альфа1,2- диапазонах при представлении движений творческого характера наблюдаются сильные когерентные связи между передними отделами левого полушария и задними отделами правого, так называемая «когнитивная ось», отражающая решение задачи имеющимся в опыте субъекта способом.

На основе результатов проведенного эмпирического исследования можно заключить о том, что характер распределения и сила внутри- и межполушарных когерентных связей коры мозга дифференцируются в зависимости от уровня профессионального мастерства, частотных диапазонов и характера представления движений, а также сформулировать следующие выводы:

1. Выявлены психофизиологические корреляты представления движений творческого и не творческого характера у исследуемых с разным уровнем танцевального мастерства, характеризующиеся особой частотно-пространственной организацией биоэлектрической активности коры головного мозга и включающие в себя основные и вариативные компоненты. К основным компонентам отнесены виды связей, которые всегда проявлялись во время представления движений, независимо от танцевального мастерства участников исследования и характера движений. Также выделены две группы вариативных компонентов психофизиологических коррелятов: виды связей, которые проявлялись в зависимости от характера представления 
движений (творческие, не творческие), и виды связей, которые проявлялись в зависимости от уровня танцевального мастерства. Выделены специфичные компоненты, характерные только для группы профессиональных танцоров во время представления движений творческого характера.

2. К основным компонентам психофизиологических коррелятов отнесены высокая внутри- и межполушарная когерентность в тета-, альфа1,2- диапазонах. Такой характер распределения когерентных связей коры мозга отражает высокую эмоциональную вовлеченность, одинаковый уровень активации коры мозга и независимое функционирование полушарий при работе с образной информацией. Также к основным компонентам психофизиологических коррелятов отнесены сильные внутриполушарные короткие когерентные связи в задних отделах правого полушария, внутриполушарные длинные между передними и задними отделами правого полушария и межполушарные длинные связи во всех частотных диапазонах.

3. К вариативным компонентам психофизиологических коррелятов представления движений отнесены специфичные распределения паттернов когерентных связей коры головного мозга во время представления движений творческого и не творческого характера, что отражает различия в стратегиях выполнения творческого и не творческого задания участниками исследования. Во время представления движений творческого характера распределение функциональных связей коры головного мозга в альфа2диапазоне связано с вовлечением в процесс образной творческой деятельности активности обоих полушарий мозга, что способствует интеграции спонтанной продукции образов и мысленному конструированию из них оригинального танца.

4. К вариативным компонентам психофизиологических коррелятов отнесены специфичные распределения паттернов когерентных связей коры головного мозга в зависимости от уровня танцевального мастерства и характера представляемых движений. В тета-диапазоне у не танцоров межполушарные передние функциональные связи значительно усиливаются во время представления движений творческого характера, тогда как у профессиональных танцоров и начинающих танцоров они слабо выражены; в то же время у профессиональных танцоров и не танцоров при представлении движений творческого характера усиливается функционирование задних межполушарных когерентных связей. Эти различия, по всей вероятности, могут объяснять отличительные особенности вовлечения механизмов произвольного внимания у исследуемых с разным уровнем танцевального мастерства. В альфа2-диапазоне у не танцоров во время представления движений не творческого характера распределение функциональных связей коры локализовано преимущественно в правом полушарии, что отражает 


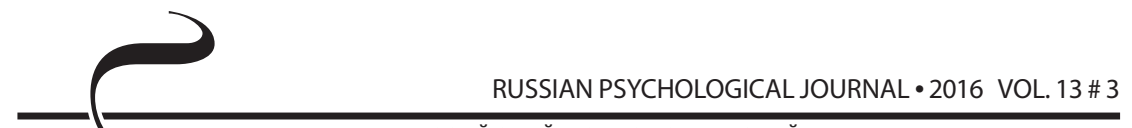

РОССИЙСКИЙ ПСИХОЛОГИЧЕСКИЙ ЖУРНАЛ • 2016 ТОМ 13 № 3

симультанный способ обработки информации, обеспечивающий эффективное генерирование новых образов.

5. Профессиональные танцоры, в отличие от других участников исследования, при представлении движений творческого характера, в отличие от не творческого, отличаются достоверно более высокими показателями когерентности ЭЭГ во всех частотных диапазонах преимущественно в задних отделах коры правого полушария мозга, а в тета- и альфа1- диапазонах в задних отделах коры левого полушария ( $p \leq 0,05)$. Такой характер распределения когерентных связей отражает разные стратегии мысленного конструирования танцевальных движений, применяемые участниками исследования в зависимости от их мастерства. Профессиональные танцоры больше ориентируются на поиск отдаленных образных ассоциаций, создание общей идеи танца. Специфичным ЭЭГ-паттерном у профессиональных танцоров при представлении движений творческого характера является активация преимущественно левополушарных отделов коры мозга при высокой межполушарной интеграции в бета-диапазоне по «оси творчества» (между передними отделами правого полушария и задними отделами левого).

Полученные результаты вносят вклад в развитие представлений в психологии и психофизиологии о психофизиологических коррелятах представления движений и мысленных образов в целом. Моделируя профессиональные ситуации и предлагая испытуемым творческие задачи, соответствующие характеру их профессиональной деятельности (мысленное представление движений творческого и не творческого характера), мы получили возможность комплексного изучения мозговых коррелятов творческого процесса в зависимости от уровня профессионального мастерства.

Также результаты исследования могут быть использованы в психофизиологии и прикладной психологии для более полного раскрытия закономерностей и механизмов развития танцевальных способностей. Данные исследования могут послужить фундаментом для разработки условий оптимизации и развития танцевальных способностей и моторной одаренности, помочь при разработке программ, использования образов и мысленного представления для повышения результатов в спорте. Результаты исследования могут быть использованы при разработке методик и технологий профессионального обучения танцоров; при разработке психологических и психофизиологических методов и приемов развития творческого потенциала личности.

\section{Литература}

1. Бехтерева Н. П., Нагорнова Ж. В. Динамика когерентности ЭЭГ при выполнении заданий на невербальную (образную) креативность // Физиология человека. - 2007. - Т. 33. - № 5. - С. 5-13. 
2. Дикая Л. А., Дикий И. С. Творческий мозг // Монография. - Ростов н/Д: Изд-во Южного федерального университета, 2015. - 216 с.

3. Дикая Л. А., Наумова М. И., Наумов И. В. Психофизиологические корреляты мысленного исполнения импровизированного танца // Российский психологический журнал. - 2015. - Т. 12. - № 4. - С. 110-126.

4. Дикий И. С., Дикая Л. А. Функциональные связи коры мозга у учащихся с моторной одаренностью при решении конвергентных и дивергентных задач // От истоков к современности: 130 лет организации психологического общества при Московском университете: Сборник материалов юбилейной конференции: В 5 томах: Том 1 / Отв. ред. Д. Б. Богоявленская. - М.: Когито-Центр, 2015. - С. 279-281.

5. Коробейникова И. И. Связь пространственной синхронизации тетадиапазона ЭЭГ человека с разной успешностью выполнения зрительно-простанственных задач // Физиология человека. - 2011. - Т. 37. № 5. - С. 26-34.

6. Разумникова О. М., Фиников С. Б. Отражение социальной креативности в особенностях активности коры на частотах дельта-, альфа2- и гамма2ритмов // Журнал высшей нервной деятельности им. И. П. Павлова. 2011. - № 6. - С. 706-715.

7. Роджерс Н. Творчество как усиление себя // Вопросы психологии. 1990. - № 3. - С. 164-168.

8. Свидерская H. Е. Особенности пространственной организации ЭЭГ и психофизиологических характеристик человека при дивергентном и конвергентном типах мышления // Физиология человека. - 2011. T. 37. - № 1. - С. 36-44.

9. Труфанов А. В., Кутасов С. Е., Соловьева Н. И., Хорохорина Т. В., Кутасова М. А., Ковалева Н. Е., Дикий И. С., Синицина Т. А. Программа спортивной подготовки по виду спорта «Каратэ». - Ростов н/Д: Изд-во Южного федерального университета, 2015. - 202 с.

10. Шкурко Т. А. Динамика отношений личности в процессе социально-психологического тренинга // Пищик В. И., Воронцов Д. В., Белоусова А. К., Вышквыркина М. А., Сериков Г. В., Шкурко Т. А., Габдулина Л. И., Бреус Е. Д., Альперович В.Д. Прикладная психология общения и межличностного познания / Под ред. Л. И. Рюмшиной. - Москва, 2015. -С. 111-120.

11. Barr K., Hall C. The use of imagery by rowers // International Journal of Sport Psychology. - 1992. - 23. - pp. 243-261.

12. Dikiy I. S., Dikaya L. A. The longitudinal study of brain correlates of creativity development // International Journal of Psychophysiology. - 2014. - V. 94. Issue 2. - P. 223. doi:10.1016/j.ijpsycho.2014.08.880

13. Fink A., Graif B., Aljoscha C., Neubauer A. Brain correlates underlying creative 
thinking: EEG alpha activity in professional vs. novice dancers // Neurolmage. 2009. - V. 46 (3). - pp. 854-862.

14. Fink A., Schwab D., Papousek I. Sensitivity of EEG upper alpha activity to cognitive and affective creativity interventions // International Journal of Psychophysiology. - 2011. -V. 82 (3). - pp. 233-239.

15. Lutzenberger W., Pulvermuller F., Birbaumer N. Words and pseudo-words elicit distinct patterns of $30 \mathrm{~Hz}$ EEG responses in human // Neuroscience Letters. - 1994. -V. 176 (1). - pp. 115-118.

16. Martin K., Moritz S., Hall C. Imagery use in sport: A literature review and applied model // The Sport Psychologist. - 1999. -V. 13. - pp. 245-268.

17. Morris T., Spittle M., Watt A. Imagery in sport. - Champaign, IL: Human Kinetics, 2005.

18. Munroe-Chandler K., Hall C., Fishburne G., Strachan L. Where, when, and why young athletes use imagery: an examination of developmental differences // Research Quarterly for Exercise and Sport. - 2007. - 78. - 1.

19. Paivio A. Cognitive and motivational functions of imagery in human performance // Canadian Journal of Applied Sport Sciences. - 1985. -V. 10 (4). pp. 22-28.

20. Ungerleider $S$. Mental training for peak performance: Top athletes reveal the mind exercises they use to excel. -Emmaus, PA: Rodale Press, 1996.

21. Vealey R., Greenleaf C. Seeing is believing: Understanding and using imagery in sport // Applied sport psychology: Personal growth to peak performance / J. Williams (ed.). - CA, 1998.

22. Von Stein A., Sarnthein J. Different frequencies for different scales of cortical integration: from local gamma to long range alpha/theta synchronization // International Journal of Psychophysiology. - 2000. V. 38. - pp. 301-313.

23. Weiss S., Rappelsberger P. EEG coherence within the $13-18 \mathrm{~Hz}$ band as a correlate of a distinct lexical organization of concrete and abstract nouns in humans // Neuroscience Letters. - 1996. -V. 209. - pp. 17-20.

\section{References}

1. Bekhtereva N. P., Nagornova Zh. V. Dinamika kogerentnosti EEG pri vypolnenii zadanii na neverbal'nuiu (obraznuiu) kreativnost' [The dynamics of the EEG coherence when performing nonverbal (imaginative) creativity tasks]. Fiziologiia cheloveka - Human Physiology, 2007, V. 33, no. 5, pp. 5-13.

2. Dikaia L. A., Dikii I. S. Tvorcheskii mozg [A creative brain]. Rostov-on-Don, Southern Federal University Publ., 2015. 216 p.

3. Dikaia L. A., Naumova M. I., Naumov I. V. Psikhofiziologicheskie korreliaty myslennogo ispolneniia improvizirovannogo tantsa [Psychophysiological 
correlates of mental dance improvisation]. Rossiiskii psikhologicheskii zhurnal - Russian Psychological Journal, 2015, V. 12, no. 4, pp. 110-126.

4. Dikii I. S., Dikaia L. A. Funktsional'nye sviazi kory mozga u uchashchikhsia s motornoi odarennost'iu pri reshenii konvergentnykh i divergentnykh zadach [Functional relations of the cortex of students with motor giftedness in solving convergent and divergent tasks]. Sbornik materialov iubileinoi konferentsii "Ot istokov k sovremennosti: 130 let organizatsii psikhologicheskogo obshchestva pri Moskovskom universitete" [Proc. the Anniversary Conference "From origins to the present: 130 years of the organization of the psychological society at Moscow University"]. Moscow, Kogito-Tsentr Publ., 2015, V. 1, pp. 279-281.

5. Korobeinikova I. I. Sviaz' prostranstvennoi sinkhronizatsii teta-diapazona EEG cheloveka s raznoi uspeshnost'iu vypolneniia zritel'no-prostanstvennykh zadach [The relationship between the spatial synchronization of the EEG theta-range of the person and the success of solving visual-dimensional task]. Fiziologiia cheloveka - Human Physiology, 2011, V. 37, no. 5, pp. 26-34.

6. Razumnikova O. M., Finikov S. B. Otrazhenie sotsial'noi kreativnosti v osobennostiakh aktivnosti kory na chastotakh del'ta-, al'fa2- i gamma2ritmov [Reflection of social creativity in the characteristics of cortical activity in delta, alpha2- and gamma2 rhythms]. Zhurnal vysshei nervnoi deiatel'nosti im. I. P. Pavlova - I. P. Pavlov Journal of Higher Nervous Activity, 2011, no. 6, pp. 706-715.

7. Rogers N. Tvorchestvo kak usilenie sebia [Creativity as self-strengthening (reinforcement)]. Voprosy psikhologii - Approaches to Psychology, 1990, no. 3, pp. 164-168.

8. Sviderskaia N. E. Osobennosti prostranstvennoi organizatsii EEG i psikhofiziologicheskikh kharakteristik cheloveka pri divergentnom i konvergentnom tipakh myshleniia [Features of the spatial organization of the EEG and psychophysiological characteristics of the person with divergent and convergent thinking styles]. Fiziologiia cheloveka-Human Physiology, 2011, V. 37, no. 1, pp. 36-44.

9. Trufanov A. V., Kutasov S. E., Solov'eva N. I., Khorokhorina T. V., Kutasova M. A., Kovaleva N. E., Dikii I. S., Sinitsina T. A. Programma sportivnoi podgotovki po vidu sporta «Karate» [The sports Karate training program]. Rostov-on-Don, Southern Federal University Publ., 2015. 202 p.

10. Shkurko T. A. Dinamika otnoshenii lichnosti v protsesse sotsial'no-psikhologicheskogo treninga [The dynamics of personal relationships in sociopsychological training]. Moscow, 2015, pp. 111-120.

11. Barr K., Hall C. The use of imagery by rowers. International Journal of Sport Psychology, 1992, 23, pp. 243-261. 
12. Dikiy I. S., Dikaya L. A. The longitudinal study of brain correlates of creativity development. International Journal of Psychophysiology, 2014, V. 94, Issue 2, P. 223. doi:10.1016/j.ijpsycho.2014.08.880

13. Fink A., Graif B., Aljoscha C., Neubauer A. Brain correlates underlying creative thinking: EEG alpha activity in professional vs. novice dancers. Neurolmage, 2009, V. 46 (3), pp. 854-862.

14. Fink A., Schwab D., Papousek I. Sensitivity of EEG upper alpha activity to cognitive and affective creativity interventions. International Journal of Psychophysiology, 2011, V. 82 (3), pp. 233-239.

15. Lutzenberger W., Pulvermuller F., Birbaumer N. Words and pseudo-words elicit distinct patterns of $30 \mathrm{~Hz}$ EEG responses in human. Neuroscience Letters, 1994, V. 176 (1), pp. 115-118.

16. Martin K., Moritz S., Hall C. Imagery use in sport: A literature review and applied model. The Sport Psychologist, 1999, V. 13, pp. 245-268.

17. Morris T., Spittle M., Watt A. Imagery in sport. Champaign, IL: Human Kinetics, 2005.

18. Munroe-Chandler K., Hall C., Fishburne G., Strachan L. Where, when, and why young athletes use imagery: an examination of developmental differences. Research Quarterly for Exercise and Sport, 2007, 78, 1.

19. Paivio A. Cognitive and motivational functions of imagery in human performance. Canadian Journal of Applied Sport Sciences, 1985, V. 10 (4), pp. 22-28.

20. Ungerleider S. Mental training for peak performance: Top athletes reveal the mind exercises they use to excel. Emmaus, PA: Rodale Press, 1996.

21. Vealey R., Greenleaf C. Seeing is believing: Understanding and using imagery in sport. Applied sport psychology: Personal growth to peak performance. J. Williams (ed.). CA, 1998.

22. Von Stein A., Sarnthein J. Different frequencies for different scales of cortical integration: from local gamma to long range alpha/theta synchronization. International Journal of Psychophysiology, 2000, V. 38, pp. 301-313.

23. Weiss S., Rappelsberger P. EEG coherence within the $13-18 \mathrm{~Hz}$ band as a correlate of a distinct lexical organization of concrete and abstract nouns in humans. Neuroscience Letters, 1996, V. 209, pp. 17-20. 